\title{
Surface Gravity Information of Nepal and its Role in Gravimetric Geoid Determination and Refinement
}

\author{
Niraj Manandhar \\ Chief Survey Officer, Survey Department, Geodetic Survey Branch \\ manandhar_niraj@hotmail.com
}

\begin{abstract}
This paper describes proposed first order gravity network which was almost abandoned and existing gravity database that has to be preserved and advocates about its importance in the determination of regional gravimetric geoid of the country. Since GPS is in full phase operation and adopted as an efficient and accurate method in position and height determination the paper also elaborates how all its three components can be taken into consideration.
\end{abstract}

\section{Introduction}

Gravimetric geoids play a major role in the process of regional geoids determination. This approach uses the set of residual gravity anomalies determined by point gravimeter measurement on the earth surface together with global geopotential models, with the geoids undulations over the oceans determined from the method of satellite altimetry.

Nepal is a country of rugged and mountainous terrain having biggest elevation differences in the country. As a result it has greatest gravity anomalies in the world's gravity field. These anomalies cause a significant effect on the survey works both in horizontal and vertical measurements. But unfortunately although the importance of the gravity measurement was felt necessary in the geodetic activities of the country its growth and further expansion cannot meet the expectation of the organization due to the lack of skilled manpower and required equipments compared to other fields of geodetic survey such as densification of the higher order controls using Global Positioning System and extension of the precise leveling network in the country.

Introduction of the global positioning system (GPS) survey operation (establishment of geodetic controls) has become much more efficient and accurate with reference to World Geodetic System 1984 (WGS84) but in the contrary it also created a challenge of the conversion of positions and heights in Everest Spheroid
1830 , which is the national datum of the country on which all the mapping activities are referred.

Secondly GPS in its relative carrier-phase mode provides three- dimensional coordinates of latitude, longitude and ellipsoidal height relative to known fixed point in the WGS84. For the transformation of horizontal coordinates (latitude and longitude) Geodetic Survey Branch has been using the local transformation where required. (Geoid for Nepal 1997).

The ellipsoidal height component must also have to be transformed to an orthometric height using information of the geoids- WGS84-ellipsoid separation at each GPS point.

Geodetic Survey Branch has been using only the horizontal component (latitude and longitude) of GPS output although the vertical component (height) is one of the vital informational product of the survey however this requirement is fulfilled by conventional method of sprit leveling till today.

\section{Conversion of ellipsoidal height}

The GPS derived ellipsoidal height is purely a geometric quantity which neglects the physical effects of the Earth's gravity field. The gravity vector provides the common experience of the vertical plumb-line, which defines the horizontal and vertical orientation of most surveying instruments used for surveying on the physical surface of the earth.

Water that is free to move will flow from higher elevation to lower elevation due to the influence of the gravity on the physical surface of the earth but in a purely geometric system it may not be true. We may then experience that the flow of water can take place from point lower to the higher side of the ellipsoidal height. Therefore the ellipsoidal height has no physical meaning hence the orthometric height which is referred to geoids must be used in surveying and engineering applications. 
In Nepal the height datum is based on Mean Sea Level of India. Hence the orthometric height is related to GPS derived ellipsoidal height at a point A by the following simple transformation.

$\mathrm{H}_{\mathrm{A}}=\mathrm{h}_{\mathrm{A}}-\mathrm{N}_{\mathrm{A}}$

Where $\mathrm{H}_{\mathrm{A}}$ is the orthometric height of point $\mathrm{A}$ above the geoids.

$\mathrm{h}_{\mathrm{A}}$ is the ellipsoidal height of point $\mathrm{A}$ above the WGS84 ellipsoid and

$\mathrm{N}_{\mathrm{A}}$ is the geoids ellipsoid separation at point $\mathrm{A}$

In the relative case, between two points $\mathrm{A}$ and $\mathrm{B}$, this relationship becomes

$$
\Delta \mathrm{H}_{\mathrm{AB}}=\Delta \mathrm{h}_{\mathrm{AB}}-\Delta \mathrm{N}_{\mathrm{AB}}
$$

Therefore, given a change in ellipsoidal height $(\Delta \mathrm{h})$ from relative GPS observation precision of the corresponding change in orthometric height $(\Delta \mathrm{H})$ is controlled, in part, by the precision with which the change in the geoids-ellipsoid separation $(\Delta \mathrm{N})$ is known. The gravimetric method using surface gravity information generates the geoids- ellipsoid separations with which to perform the transformation. The accuracy of the gravimetric method is a function of the coverage of gravity data, spatial density and accuracy of the data used in the computation of the geoids height.

\section{Relationship of gravity (g) with orthometric height $(\mathrm{H})$}

The fundamental relationship between the Earth's gravity field (g), orthometric height $(\mathrm{H})$ and the gravity potential $(\mathrm{W})$ is given by the following derivative (Heiskanen and Moritz, 1997)

$$
\mathrm{dW}=-\mathrm{gdH}
$$

As the Earth' gravity field is spatially variant, so must be the relationship between $\mathrm{W}$ and $\mathrm{H}$. This equation explains the reason behind the sprit leveling loop, even though it is error free will not close and the geoids is a unique equipotential surface ( $\mathrm{W}=$ constant) of the earth's gravity field which is closely related to mean sea surface. Hence geoid is closed and continuous surface which undulates in and irregular fashion because of the mass density variations within the earth.

Now in order to determine the geoids using the gravimetric method, observed gravity on the earth's surface must at first be reduced to geoids by accounting for the observation elevation, whist preserving the earths mass. At present during the process of geoids determination, the Faye gravity anomaly $(\Delta \mathrm{g})$ is used, which is computed by adding the gravimetric terrain correction to the free-air gravity anomaly.

$$
\Delta \mathrm{g}=\Delta \mathrm{g}_{\mathrm{FA}}-\mathrm{C}
$$

Where $\Delta \mathrm{g}_{\mathrm{FA}}$ is the second -order free-air gravity anomaly, computed using the procedure described in Featherstone (1995) and $\mathrm{C}$ is the gravimetric terrain correction (Moriť, 1968).

$$
C=\frac{G r R^{2}}{2} \int_{\mathrm{s}} \frac{\left(H^{\prime}-H\right)^{2}}{l^{3}} d \mathrm{~s}
$$

Where : $\mathrm{G}$ is the Newtonian gravitational constant

$\rho$ is the topographic density, assumed to be a constant $2670 \mathrm{kgm}^{-3}$

$\mathrm{R}$ is the mean radius of the earth,

$\mathrm{H}$ height of the computation point,

$\mathrm{H}^{\prime}$ is the height of each distant point,

$l$ is the separation and

$d \sigma$ is and integration element on the sphere.

\section{Relationship between geoids height $(N)$ and gravity anomalies $(\Delta \mathrm{g})$}

The fundamental relationship between the geoids height $(\mathrm{N})$ and gravity anomalies ( ) is given by the Stokes's formula (Heiskanen and Moritz, 1967). However, this formula requires that gravity data are used over the entire earth, which is an onerous condition that is not currently satisfied. Instead, a remove-restore approach is adopted, which significantly reduces the data and the computational requirements. It also reduces the effect of the spherical approximations inherent in the Stokes's formula. During this remove-restore approach, a global geopotential model (GGM) provides the long wavelengths geoids undulations and Stokes's formula adds those wavelengths greater than that implied by the resolution of the gravity and the terrain data. In the mathematical form, Stokes's formula in conjunction with the remove-restore technique is given by,

$$
\begin{gathered}
N=N_{G G M}+\frac{R}{4 \pi \gamma} \int_{\sigma} \mathrm{S}(\Psi)\left(\Delta \mathrm{g}-\Delta \mathrm{g}_{\mathrm{GGM}}\right) \mathrm{d} \sigma \\
N_{G G M}=\frac{G M}{r \gamma} \sum_{n=2}^{M \max }\left(\frac{a}{r}\right)^{n} \sum_{m=0}^{n}\left(\delta \bar{C}_{n m} \operatorname{Cos} m \lambda+\bar{S}_{n m} \operatorname{Sinm} \lambda\right) \bar{P}_{n m}(\operatorname{Cos} \theta)
\end{gathered}
$$




$$
\Delta g_{G G M}=\frac{G M}{r^{2}} \sum_{n=2}^{M \max }\left(\frac{a}{r}\right)^{n}(n-1) \sum_{m=0}^{n}\left(\delta \bar{C}_{m} \operatorname{Cos} m \lambda+\bar{S}_{m} \operatorname{Sinm} \lambda\right) \bar{P}_{m}(\operatorname{Cos} \theta)
$$

Where,

$\gamma$ is the mean normal gravity

$S(\psi)$ is the stokes's function

$\Delta \mathrm{g}$ are the Faye (terrain corrected free-air) gravity anomalies

$\psi$ is the angular distance from the computational point to the roving point,

$G M$ is the geocentric gravitational constant

$(r, \theta, \lambda)$ are the spherical polar coordinates of the computational point

$\bar{P}_{n m}$ are the fully normalized associated Legendre polynomials for degree $\mathrm{n}$ and order $\mathrm{m}$ and

$\delta \bar{C}_{n m}$ and $\bar{S}_{n m}$ are fully normalized spherical harmonic coefficients of the GGM, which has been reduced by the even zonal harmonics of the reference ellipsoid, and are complete to degree and order $M_{\max }$.

In equation (6) the gravity anomaly used is the Faye gravity anomalies hence it generates Faye co-geoid which must be converted to true geoids by adding the indirect effect $\left(N_{\mathrm{i}}\right)$ corresponding to the free-air reduction and gravimetric terrain correction. This indirect effect is given by Wichiencharoen (1982) as,

$$
N_{i}=-\frac{\pi \mathrm{G} \rho \mathrm{H}^{2}}{\gamma}-\frac{G \rho R^{2}}{6 \gamma} \int_{\sigma} \frac{\left(H^{\prime 3}-H^{3}\right)}{l^{3}} d \sigma
$$

\section{Numbering of the gravity stations:}

The number of the first order gravity station consists of two or three digits where the last number is always designated by digit " 1 " signifying it as the first order. The preceding numbers before the digit " 1 " is the serial number of the stations within the first order network. Similarly the numbering of the second order gravity stations consists of the number two or more digits where the last number is always designated by digit " 2 " marking it as second order.

\section{Gravity observation:}

During the period 1981-1984 British Military Survey units were engaged in establishing the geodetic control network in Nepal. During this period some gravity was also observed to establish the gravity base in the country. The gravity reference system used for the gravity survey was IGSN 1971 and the instruments used for the gravity observation in 1981-1984 survey were Lacoste Romberg Model G gravity meter.

During 1981-84 survey 21 out of 36 stations were observed by MODUK (Ministry of Defense United Kingdom) but these stations were not monumented during the time of observation. These stations need to be monumented at the designated site according to the MODUK's Gravity Base Station Description (Reports and Results of Gravity Survey in Nepal).

\section{Fundamental Gravity Base:}

The fundamental gravity base station of Nepal was established at Tribhuwan International Airport of Kathmandu. This station is designated as Kathmandu J. In May 1981 a gravity transfer was made from station Kathmandu $\mathrm{J}$ to and IGSN 71 station in Bangkok. The sequence of measurement was Kath/Bangkok/Kath. The time taken for the observation was 33 hours with 13 hours layover in Bangkok. Four gravimeters were used to determine the difference in " $g$ ". The mean value obtained for the difference in " $\mathrm{g}$ " was $+361.12 \mathrm{mGal}$.

Apart from the fundamental gravity base most of the gravity base stations were established at the airports and in such locations where communication by road was possible. The main net consists of 45 stations at 35 different locations in the country.

For most of the detail stations the position and elevation has been taken form the best available map source during that time.

\section{Gravity Detail Stations:}

Values of the observed gravity were determined at a total of 375 detail stations. Trip to fix the detail station from a reference base station were made using single gravity meter so that no reliability can be quoted for the gravity values. However from the various evidience the Se (Standard error) of uncertainty of gravity values is unlikely to exceed +/- $0.3 \mathrm{mGal}$ relative to IGSN 71 reference system. This observation were made by MODUK.

The Eastern Nepal Topographic Mapping Project( ENTMP) observed new gravity in 43 GPS stations. The gravity data set of ENTMP includes 95 gravity measurements specified as old British points. This information created confusion whether the old British points means the gravity observation made by MODUK or the new gravity observation made by ENTMP on the trig. Stations established by British Survey Team. However it is not a serious problem because the common points in the data set can be detected. 


\section{Gravity network of Nepal}

The first order gravity network consists of thirty-six (36) stations situated in different parts of the country. These gravity stations are mainly located at airports and airstrips where ever possible focusing on the need easy accessibility for the observation. There are 25 such sites located in airport and airstrips and the remaining eleven (11) stations are located in district offices or in other Government offices where it can be perfectly protected such as police stations and army barracks etc. The distribution of the first order gravity stations enables for the break down of the second order gravity positions in future.

List of the first order gravity stations are as follows:

Table 1

\begin{tabular}{|c|c|c|c|c|c|c|c|}
\hline \multicolumn{2}{|r|}{ Station } & \multicolumn{2}{|c|}{ Access By } & \multicolumn{2}{|c|}{ Monumentation } & \multirow[t]{2}{*}{ Observed By } & \multirow[t]{2}{*}{ Remarks } \\
\hline No. & Name & Air & Road & Present & Proposed & & \\
\hline 11 & NAGARKOT & & & PILLAR & $\mathrm{CBL}+\mathrm{BM}$ & MODUK & \\
\hline 21 & KATHMANDU & & & $\mathrm{CBL}+\mathrm{BM}$ & - & MODUK & \\
\hline 31 & LAMOSANGU & & & - & $\mathrm{CBL}+\mathrm{BM}$ & MODUK & \\
\hline 41 & KODARI & & & $\mathrm{CBL}+\mathrm{BM}$ & - & MODUK & \\
\hline 51 & JIRI & & & - & $\mathrm{CBL}+\mathrm{BM}$ & - & \\
\hline 61 & LUKLA & & & - & $\mathrm{CBL}+\mathrm{BM}$ & - & \\
\hline 71 & RUMJATAR & & & - & $\mathrm{CBL}+\mathrm{BM}$ & - & \\
\hline 81 & TAPLEJUNG & & & - & $\mathrm{CBL}+\mathrm{BM}$ & & \\
\hline 91 & BHADRAPUR & & & - & $\mathrm{BM}$ & MODUK & \\
\hline 101 & DHANKUTA & & & - & $\mathrm{CBL}+\mathrm{BM}$ & - & \\
\hline 111 & BIRATNAGAR & & & & $\mathrm{BM}$ & MODUK & \\
\hline 121 & RAJBIRAJ & & & - & $\mathrm{CBL}+\mathrm{BM}$ & MODUK & \\
\hline 131 & JANAKPUR & & & $\mathrm{CBL}+\mathrm{BM}$ & - & MODUK & \\
\hline 141 & NAWALPUR & & & - & $\mathrm{CBL}+\mathrm{BM}$ & MODUK & \\
\hline 151 & BIRGUNJ & & & - & $\mathrm{BM}$ & MODUK & \\
\hline 161 & HETAUDA & & & - & $\mathrm{BM}$ & MODUK & \\
\hline 171 & TRISULI & & & - & $\mathrm{CBL}+\mathrm{BM}$ & - & \\
\hline 181 & GORKHA & & & - & $\mathrm{CBL}+\mathrm{BM}$ & - & \\
\hline 191 & BHARATPUR & & & - & $\mathrm{CBL}+\mathrm{BM}$ & MODUK & \\
\hline 201 & POKHARA & & & - & $\mathrm{BM}$ & MODUK & POKHARA J, JA \\
\hline 211 & JOMSOM & & & - & $\mathrm{CBL}+\mathrm{BM}$ & - & \\
\hline 221 & BAGLUN & & & - & $\mathrm{CBL}+\mathrm{BM}$ & MODUK & \\
\hline 231 & TANSEN & & & - & $\mathrm{CBL}+\mathrm{BM}$ & - & \\
\hline 241 & SIDARTHA NAGAR & & & - & $\mathrm{BM}$ & MODUK & BHAIRA WA, J \\
\hline 251 & LAMAHI & & & & $\mathrm{CBL}+\mathrm{BM}$ & MODUK & \\
\hline 261 & BAJHYAN (ROLPA) & & & - & $\mathrm{CBL}+\mathrm{BM}$ & - & \\
\hline
\end{tabular}




\begin{tabular}{|l|l|c|c|c|c|c|l|}
\hline 271 & JUPHAL (DOLPA) & & & - & CBL+BM & - & \\
\hline 281 & JUMLA & & & - & $\mathrm{CBL}+\mathrm{BM}$ & - & \\
\hline 291 & CHAUR JAHARI & & & - & $\mathrm{BM}$ & MODUK & CHAUR JAHARI, J \\
\hline 301 & NEPALGUNJ & & & - & $\mathrm{BM}$ & MODUK & NEPALGUNJ, JA \\
\hline 311 & BIRENDRA NAGAR & & & - & $\mathrm{BM}$ & MODUK & SURKHET J \\
\hline 321 & SIMIKOT & & & - & $\mathrm{CBL}+\mathrm{BM}$ & - & \\
\hline 331 & CHAINPUR (BAJHAG) & & & - & $\mathrm{CBL}+\mathrm{BM}$ & - & \\
\hline 341 & DIPAYAL & & & & $\mathrm{BM}$ & MODUK & DOTI, J \\
\hline 351 & PATAN (BAITADI) & & & - & $\mathrm{CBL}+\mathrm{BM}$ & - & \\
\hline 361 & DHANGADHI & & & - & $\mathrm{BM}$ & MODUK & DHANGA DHI D, J \\
\hline
\end{tabular}

Notes:

$\mathrm{CBL}+\mathrm{BM}$ means Concrete Block Pillar with Bench Mark

BM means Bench Mark

MODUK means Ministry of Defense United Kingdom

This first order gravity network need to revisited, checked and if the station was not monumented the Monumentation work have to be carried out at the earliest in near very future otherwise all the valuable information might be lost.

\section{Geoid Computation}

One of the oldest methods of geoid computation is the astro-geodetic method. In the first order network of Nepal 84 points have astro-geodetic deflection components and geoid heights expressed in Nepal datum. Then for the evaluation of geoid height " $N$ " of the unknown point a graphical method was used. The geoid chart was drawn with the help of astro-geodetic values of "deflections from vertical", the geoid height of the new point was interpolated from the existing chart. It was one of the earliest and simplest method. At present due to the advent of various mapping software and computers the interpolation of data by electronic device make faster and more accurate when dealing with the large data set. This method is almost primitive method of geoid computation. Hence the new gravimetric geoid using the above mentioned gravity data base the Gravimetric Geoid97 was computed by Finnish Geodetic Institute during the Eastern Nepal Topographic Mapping Project in 1997. The geoid NEPAL97 for the whole of Nepal was computed using materials (GPS, Leveling, Gravimetry) data collected over many years in both east and west Nepal. The technique used was "GPSgravimetric". First a gravimetric geoid was computed using geopotential models then this gravimetric geoid was "fitted" to a set of geoid undulation values obtained from the GPS heighting as well as spirit leveling. This geoid has not been used yet in the geodetic computation because the data was not made available to Geodetic Survey Branch.

\section{Conclusion and Recommendations}

Fundamental geodetic network is required for general mapping, environmental studies, development of communication system, irrigation, water supply and hydropower as well as crustal dynamics. In other words in most of the major activities of national level projects there are fundamental roles of geo-information based on geodetic controls.

Quick and efficient method of providing horizontal and vertical controls are todays requirement. At present this requirement is fulfilled by the method of Global Positioning System but sometimes the output that the GPS provides may not be relevant or meaningful to the requirement that is demanded. For example GPS provides horizontal controls based on WGS84 and in the mean time gives the height above this ellipsoid.

In order to develop the conversion parameters different geodetic measurement on the physical surface of the earth is the prerequisite. This includes many types of geodetic information such as angles, distances, heights, gravity, positions etc. These all are raw vital information. These information cannot be collected in one day. The huge amount of time, money and skilled human labor was spent in its acquisition. Since it is a base for infrastructure development of the nation, government make investment in this field or even sometimes co-operates with developed countries in order to fulfill the technical skill and modern 
technology that is lagging in the country. All such information should be protected and preserved

In the geodetic satellite positioning heights can, however not be obtained directly from the GPS measurement, but in the present context one of the main objective is using GPS with full potential which means replacement of the geodetic sprit leveling.

This requires high resolution gravimetric geoid with dense coverage of gravity and terrain data. Therefore the point surface gravity information should be desified otherwise the densification works has to be replaced by airborne gravity survey. At present airborne gravity survey can achieve an accuracy of $2 \mathrm{mGal}$ in gravity data acquisition.

\section{References}

1) Final Reports of Ground Control Surveys Vol. III Definition of Gravimetric Geoid.

2) Featherstone W.E., 1995On the use of Australian Geodetic Datums in the gravity field determination. Geomatics Research Australasia, 61
3) Heiskanen, W. A. H. Moritz Physical Geodesy, Freeman San Francisco 1967

4) Moritz, H (1980a) Geodetic Reference System 1980 (GRS80) Bulletin Geodesique Vol 54 pp. 395-405

5) Manandhar, N. : Geoid Studies of Nepal, Thesis submitted for Master of Engineering, School of Geomatic Engineering, University of New South Wales, Sydney.

6) Manandhar, N. : Report on Topographic Map Preparation of Geodetic Observatory Nagarkot.

7) Reports and Results of Gravity Survey in Nepal, 1981-1984

8) The Defense Mapping Agency (1987). DMA Technical Report (Supplement to Department of Defence World Geodetic System 1984 Technical Report) Part 1: Methods, Techniques, and Data Used in WGS84 Development, DMA TR, 8350. 2 -A, Washington DC. 1 Dec. 1987.

9) Torge, W. (1991) Geodesy. 2nd Edition. Walter de Gruyter: Berlin, 1991. 